\title{
A rat model for functional characterization of pregnancy-induced denervation and postpartum reinnervation in the myometrium and cervix: a superfusion study
}

\author{
I Zupkó, D Csonka and G Falkay \\ Department of Pharmacodynamics and Biopharmacy, University of Szeged, Szeged, Hungary \\ Correspondence should be addressed to G Falkay, Szeged, Eötvös u. 6, H-6721, Hungary; \\ Email: falkay@pharma.szote.u-szeged.hu
}

\begin{abstract}
The pregnancy-induced rapid degeneration of the adrenergic nerves innervating the uterus is a well-known but poorly understood phenomenon. Since most of the published investigations were carried out by histological assay, our aim was to describe the loss of the adrenergic function during pregnancy and the reinnervational procedure in the postpartum period. Myometrial and cervical samples from rats were loaded with $\left[{ }^{3} \mathrm{H}\right]$ noradrenaline and then transferred into a chamber for superfusion. After a wash-out period, fractions were collected. The fifth and fifteenth fraction tissues were stimulated with an electric field. The $\left[{ }^{3} \mathrm{H}\right]$ noradrenaline contents of the fractions were determined, together with the amount remaining in the tissue. The myometrial $\left[{ }^{3} \mathrm{H}\right]$ noradrenaline release was substantially decreased in early pregnancy, and absent in the late stage. Differences in release profile were detected between the implantation sites and the interimplantation areas. As a refinement of the results of previous histochemical studies, the noradrenergic functions of the cervix were found to be deeply affected in the early postpartum period. The pregnancy-induced denervational procedure can be followed by means of a superfusional technique after $\left[{ }^{3} \mathrm{H}\right]$ noradrenaline loading. As our technique is considered to be similar in sensitivity to histological methods, superfusion can be regarded as a model for functional investigations of pregnancy-induced denervation.
\end{abstract}

Reproduction (2005) $130743-749$

\section{Introduction}

Pregnancy induces dramatic changes in practically all of the physiological functions in mammals, including hormonal environment and metabolic status, but the most impressive changes are restricted to the reproductive organs. Beside the several-fold increase in the mass of the myometrial smooth muscle, the uterus undergoes a wellcharacterized but little understood remodelling of its innervation. The uterus of the non-pregnant rat is supplied by adrenergic (Adham \& Schenk 1969), cholinergic (Bell 1972) and peptidergic fibres (Papka et al. 1985), all of them innervating both the vasculature of the myometrium and the smooth muscle itself. This remodelling involves a profound denervation procedure, in which the histologically visualized density of these nerves decreases substantially as the gestation continues, and a reinnervational process starts after delivery (Haase et al. 1997). The degeneration of the nerves was initially presumed to be restricted to the adrenergic system (Thorbert et al. 1979), but a large body of evidence now indicates that all of the nerves in the uterus, including the cholinergic and peptidergic fibres, undergo this denervation during gestation (Hervonen et al. 1973, Moustafa 1988, Haase et al. 1997). The decreased amounts of functional storage vesicles in the uteri of guinea-pigs at term pregnancy are consistent with the proposed pregnancy-induced degeneration of adrenergic nerves (Fried et al. 1985). As the adrenergic system plays a crucial role in the regulation of the contractility of the pregnant uterus, the degeneration of the adrenergic nerves of the uterus is concluded to be most important, and this phenomenon is subjected to the most intensive investigation. Ultrastructural characterization of pregnancyinduced adrenergic denervation is frequent, with most studies applying immunohistochemical methods. These techniques are suitable for a detailed description of the progression of the denervational procedure and for differentiating between the innervation of the smooth muscle and that of the vessels supplying the myometrium. It is conceivable, however, that there could be some functional change in the uterine innervation that can be detected before signs of degeneration of the nerve. Investigation of the pharmacological reactivity and a description of the adrenergic receptor status as a function of the gestation 
could be regarded as a functional approach to myometrial denervation (Engstrom et al. 1997). When these methods are used, however, the final conclusion is influenced by numerous other factors which are also reported to change during pregnancy; for example, the density and affinity of the targeted receptor, and its coupling to the signal mechanism (Legrand et al. 1993, Mhaouty et al. 1995). Accordingly, the aim of our present work was to describe an animal model that is suitable for characterizing the adrenergic denervation of the pregnant uterus, and the reinnervation in the postpartum period, from a purely functional aspect. We hypothesized that deterioration or loss of the function of the adrenergic fibres occurs earlier than the structural changes during pregnancy, and the function recovers later than the structure after delivery. As the presynaptic uptake and stimulated release of the transmitter can be regarded as a functional marker of the adrenergic nerves, a superfusion technique was chosen. With this method, the electrically evoked release of $\left[{ }^{3} \mathrm{H}\right]$ noradrenaline was investigated as a function of gestational age and in the early postpartum period. As the histological data suggest that the cervical adrenergic innervation remains intact or little affected, whereas only limited data are available on its functional changes during pregnancy, cervical samples were additionally investigated by the same method (Bryman et al. 1987, Lundberg et al. 1987, Nostrom \& Bryman 1989).

\section{Materials and Methods}

Sprague-Dawley rats (200-250 g for females) were mated in a special cage in the early morning; copulation was determined by the presence of a copulation plug or sperm in a native vaginal smear. The day of conception was considered to be the first day of pregnancy.

\section{Release of $\left[{ }^{3} \mathrm{H}\right]$ noradrenaline}

Pregnant and non-pregnant female Sprague-Dawley rats were killed by cervical dislocation. Samples of uterine and cervical tissue $(20-30 \mathrm{mg})$ were dissected; the samples from the implantation and interimplantation sites were processed separately. Myometrial samples were cleared from connective tissue and endometrium. The wet weights of the samples were measured, and they were minced and incubated with $10^{-7} \mathrm{M}\left[{ }^{3} \mathrm{H}\right]$ noradrenaline at $37^{\circ} \mathrm{C}$ for $60 \mathrm{~min}$. The samples were then washed three times with de Jongh buffer, and the pieces were placed into superfusion chambers (Experimetria, Budapest, Hungary), which were superfused continuously for $60 \mathrm{~min}$ at a flow rate of $1 \mathrm{ml} / \mathrm{min}$ with de Jongh buffer containing the monoamine oxidase (MAO) inhibitor pargyline, the noradrenaline-reuptake inhibitor desipramine and the extraneuronal reuptake inhibitor deoxycorticosterone (each $10 \mathrm{mM}$ ). The composition of the buffer was 137 $\mathrm{mM} \mathrm{NaCl}, 3 \mathrm{mM} \mathrm{KCl}, 1 \mathrm{mM} \mathrm{CaCl}, 1 \mathrm{mM} \mathrm{MgCl}, 12 \mathrm{mM}$ $\mathrm{NaHCO}_{3}, 4 \mathrm{mM} \mathrm{Na}_{2} \mathrm{HPO}_{4}$ and $6 \mathrm{mM}$ glucose, $\mathrm{pH}$ 7.4.
The solution was maintained at $37^{\circ} \mathrm{C}$ and equilibrated throughout the experiment with $\mathrm{O}_{2}$ containing $5 \%(\mathrm{v} / \mathrm{v})$ $\mathrm{CO}_{2}$. After a 60-min wash-out period, a total of 22 3-min fractions were collected. At the end of the experiment, the tissue samples were solubilized in $1 \mathrm{ml}$ Solvable (Canberra-Packard, Budapest, Hungary) for $3 \mathrm{~h}$ at $60^{\circ} \mathrm{C}$. The ${ }^{3} \mathrm{H}$ content in each 3-min fraction and tissue solution was determined with a liquid scintillation spectrometer.

Electrical field stimulation (EFS) consisting of squarewave pulses was applied to the tissues, using a programmable stimulator (Experimetria). EFS was applied twice after the wash-out period, during fractions 5 and 15. Each period of stimulation consisted of 360 pulses (voltage, 40 $\mathrm{V}$; pulse width, $2 \mathrm{~ms}$; frequency, $2 \mathrm{~Hz}$; these parameters are suitable for neural stimulation).

The $\left[{ }^{3} \mathrm{H}\right]$ noradrenaline contents in the fractions were expressed as fractional release. This is the amount of labelled transmitter liberated during a 3-min fraction as a percentage of the actual radioactivity content in the tissue at the time of sampling. Peak releases were calculated by subtraction of the radioactivity of the fourth and fourteenth fractions from that of the fifth and fifteenth fractions, respectively. All experimental animal protocols satisfied the Guidelines for Animal Experimentation approved by the Animal Experimentation Committee of the University of Szeged.

\section{Drugs}

Pargyline, desipramine and deoxycorticosterone were from Sigma-Aldrich (Budapest, Hungary). (-)-7- $\left[{ }^{3} \mathrm{H}\right](\mathrm{N})-\mathrm{Nor}-$ adrenaline hydrochloride (specific activity, $7.94 \mathrm{Ci} / \mathrm{mmol}$ ) was from Perkin Elmer Life Sciences (Boston, MA, USA).

\section{Statistical analysis}

Differences between mean values were evaluated by using one-way analysis of variance (ANOVA) with Dunnett's post hoc test. Differences between implantation and interimplantation sites were evaluated by using the unpaired $t$ test. Statistical analysis of the data was performed with GraphPad Prism 2.01 (Graph Pad Software, San Diego, CA, USA). All reported data are mean results from at least six independent experiments.

\section{Results}

\section{Results of tissue activity determination}

The tissue activity (expressed in d.p.m./mg tissue) was used to describe the uptake capacity of the sample for $\left[{ }^{3} \mathrm{H}\right]$ noradrenaline. This was highest in the non-pregnant state and a gradual decrease was seen during pregnancy (Fig. 1). On day 7 , tissue uptake of the labelled transmitter for the implantation sample was significantly less than that for the interimplantation myometrium. A similar trend was experienced in the cervix, resulting in a significantly lower tissue activity from day 14 . As far as the postpartum period was 


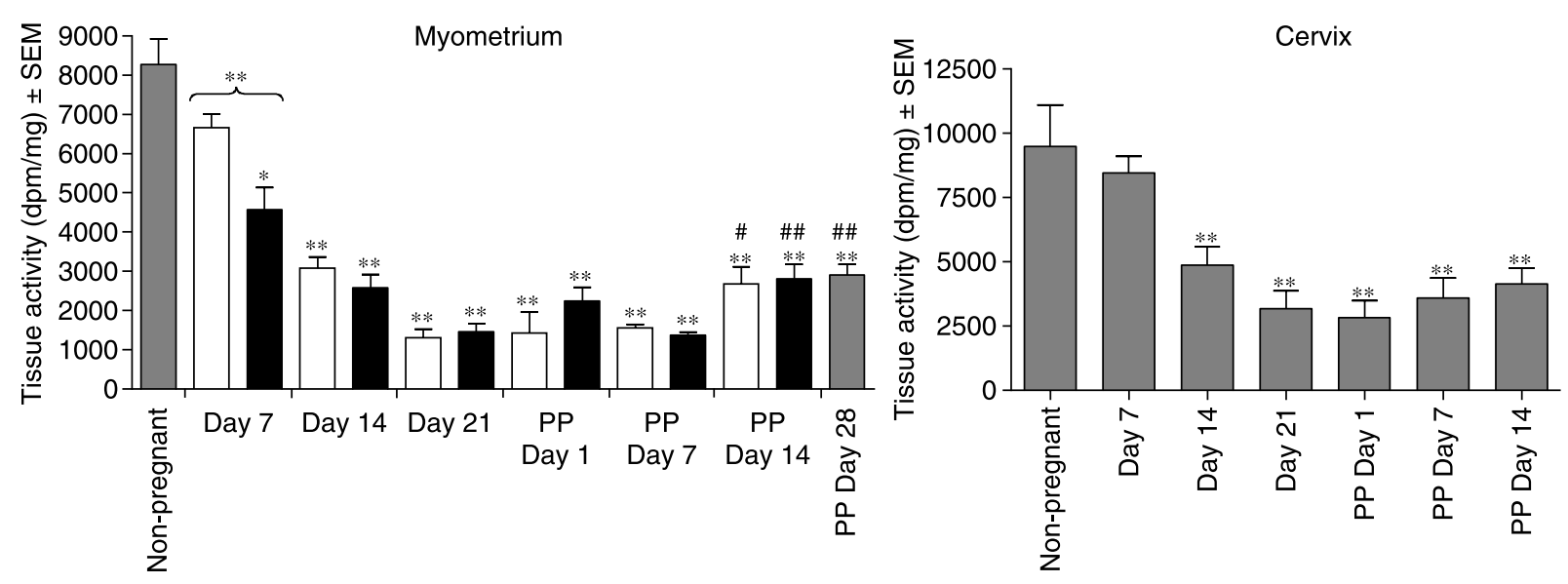

Figure $1\left[{ }^{3} \mathrm{H}\right]$ Noradrenaline-uptake capacity of myometrial and cervical samples during gestation and the postpartum (PP) period. * and ** denote $P<0.05$ and $P<0.01$ as compared with the non-pregnant value, respectively; \# and \#\# denote $P<0.05$ and $P<0.01$ as compared with the day-21 values, respectively. Black bars, implantation sites; white columns, interimplantation sites (distinction between the two sites is not possible 21 days after delivery).

concerned, tissue activity of the uterus at both the implantation and interimplantation sites and in the cervix remained lower than before pregnancy throughout the 28 days of the investigation. In contrast with the period of pregnancy, no site-dependent difference was observed in the myometrium. However, when the postpartum results were compared with the day-21 results, the myometrial samples displayed significantly higher values after 14 days, which points to a slow but detectable reinnervation procedure. The tissue activities of the postpartum cervical samples were not higher than the day 21 value.

\section{Results of stimulated $\left[{ }^{3} \mathrm{H}\right]$ noradrenaline release}

EFS evoked a substantial $\left[{ }^{3} \mathrm{H}\right]$ noradrenaline release in both the uterus and the cervix isolated from non-pregnant rats (Figs 2 and 3). Two EFSs were applied to obtain information on the release capacity of the tested tissue. The second stimulus resulted in a smaller transmitter peak than the first. In the myometrial tissue, a gradual decrease was detected in the peak evoked by EFS during the gestation. The amount of $\left[{ }^{3} \mathrm{H}\right]$ transmitter released became less and less as the pregnancy progressed, and a gradual increase could be measured during the first 28 days of the postpartum period (Fig. 4). In general, it was found that the peak elicited by the second EFS decreased in a more sensitive way than did the first one; that is, as compared with the non-pregnant results a significant difference $(P<0.01)$ could be detected earlier: day 7 versus day 21 for the second and first peaks, respectively (Fig. 2). A substantial and significant difference was found between the implantation and interimplantation sites of the uterus in the early pregnant state, indicating that the loss of the adrenergic nerve function starts in the implantation area. As concerns the cervical samples, a gradual tendency of the EFS-evoked $\left[{ }^{3} \mathrm{H}\right]$ noradrenaline release to decrease was observed during pregnancy, but these changes were not significant statistically (Fig. 3).
In the postpartum period, a gradual increase in the function of the noradrenergic nerves could be demonstrated in the uterus, but even after 28 days the EFSinduced release was reduced and the stimulated release of $\left[{ }^{3} \mathrm{H}\right]$ noradrenaline was not significantly different from that on the last day of pregnancy. In contrast with the denervational process, reinnervation could be detected only in the first peak. It is assumed that the first EFS exhausted the limited transmitter capacity of the regenerating nerves, resulting in a decreased second peak. The EFS-evoked release of $\left[{ }^{3} \mathrm{H}\right]$ noradrenaline from the cervical samples was significantly suppressed in the early postpartum period, and approximated the non-pregnant level 14 days after delivery (Fig. 3). Cervical adrenergic reinnervation was followed only up to postpartum day 14 .

\section{Discussion}

Degeneration of the adrenergic nerves in the uterus during pregnancy is a well-described phenomenon in the guineapig (Bell \& Malcolm 1978), rat (Haase et al. 1997) and human (Wikland et al. 1984). Its common occurrence in mammals suggests that this kind of uterine denervation is of physiological importance, contributing to the quiescence of the uterus during pregnancy. Since activation of the sympathetic system would result in increases in myometrial contractility and vasoconstriction, the loss of the adrenergic fibres may prevent all of these potentially harmful consequences (Owman 1981). In view of the fact that the denervated myometrial arteries become dilated and only the larger arteries retain their innervation, it seems conceivable that these larger vessels take over the control of the uteroplacental resistance, permitting an elevated blood flow (Haase et al. 1997). This finding is in accordance with the report of a pregnancy-induced increase in the nerve fibres in the uterine artery of the guinea-pig (Mione \& Gabella 1991). 

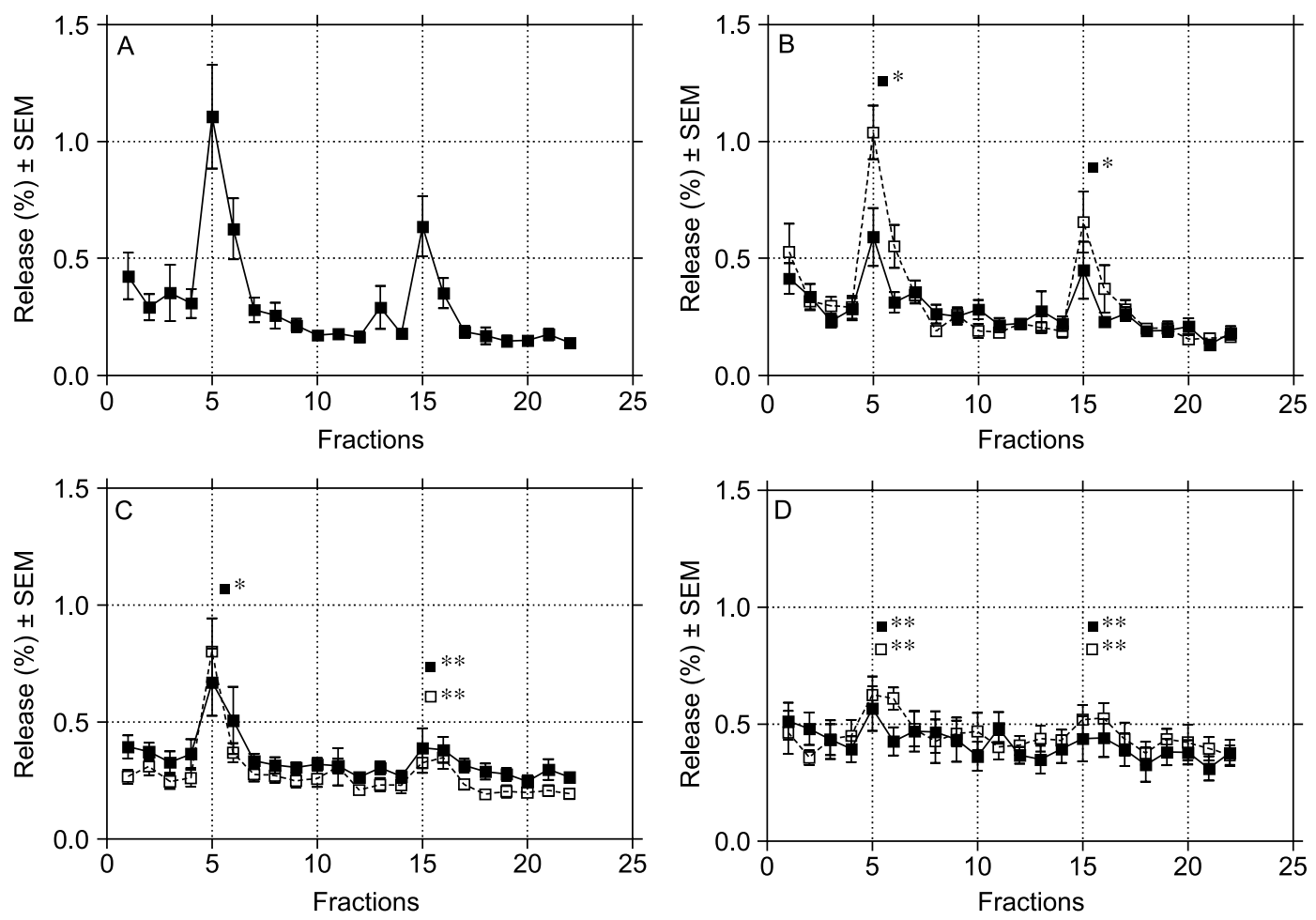

Figure 2 EFS-evoked fractional $\left[{ }^{3} \mathrm{H}\right]$ noradrenaline release from myometrial samples at oestrus (A), and on days 7 (B), 14 (C) and 21 (D) of pregnancy. * and ** denote $P<0.05$ and $P<0.01$ as compared with the non-pregnant value, respectively. During gestation, $\square$ and $\square$ indicate release from the implantation and interimplantation sites, respectively.

It is not clear at present how this denervational phenomenon is evoked, and whether it is generalized or not. The fact that the implantation area becomes denervated first favours a causative factor of foetoplacental origin. This is in line with the unchanged innervation of the uterine-horn-devoid foetus of the late-pregnant guinea-pig (Lundberg et al. 1987). However, a large body of evidence indicates that the innervation of the uterus demonstrates pregnancy-independent plasticity, and physiological factors such as puberty, the oestrus cycle and sexual steroid manipulations can result in changes - either increases or decreases - in the nerve pattern (Van Orden et al. 1980, Juorio et al. 1989, Brauer et al. 1992, Zuobina \& Smith 2001). Uterine hyperinnervation has also been reported in oestrogen receptor-knockout mice, which is a further argument in favour of a generalized mechanism responsible for denervation (Zuobina \& Smith 2001). As the basic reason for the phenomenon is unknown, the time of its initiation is also incompletely defined.

We examined the decrease in function of the adrenergic neurones, a functional approach that is concluded to have two advantages. Firstly, we could detect a significant decrease in the function of the myometrial adrenergic nerves as early as day 7 of pregnancy. Although histochemical examination was not a part of our present study, it was reported previously to be detectable at the end of the second third of pregnancy (Klukovits et al. 2002). At the end of the first third of pregnancy, there were significant differences in noradrenaline release and uptake between the implantation and interimplantation sites. This suggests that there are also foetoplacental factors responsible for the pregnancy-induced adrenergic denervation. The results of uptake capacity are presented as d.p.m./mg tissue without normalization for a substantially increasing myometrial weight during gestation. The distinction between areas within a uterine horn made our results inappropriate for normalization, as decreasing uptake capacity during gestation is considered to be a consequence of the degeneration of the adrenergic nerves and a dilution of the remaining fibres. On the other hand, the interpretation of the release of the transmitter - that is, the fractional release - is independent of the weight of the sample and that of the organ taken, meaning that it reflects purely the functional deterioration of the sympathetic system.

A further advantage of the approach used here is the ability to detect functional change which cannot be followed by structural investigations. The innervation of the cervix is reported to be unchanged in humans (Bryman et al. 1987, Nostrom \& Bryman 1989) and in the guineapig during pregnancy (Alm et al. 1979, Lundberg et al. 1987). Only limited data are available on the rat. Our results clearly reveal a substantial functional deterioration in the cervix, disclosed by the transmitter uptake capacity, but not by the EFS-evoked release. It could be suggested, therefore, that this capacity is a more sensitive feature of 

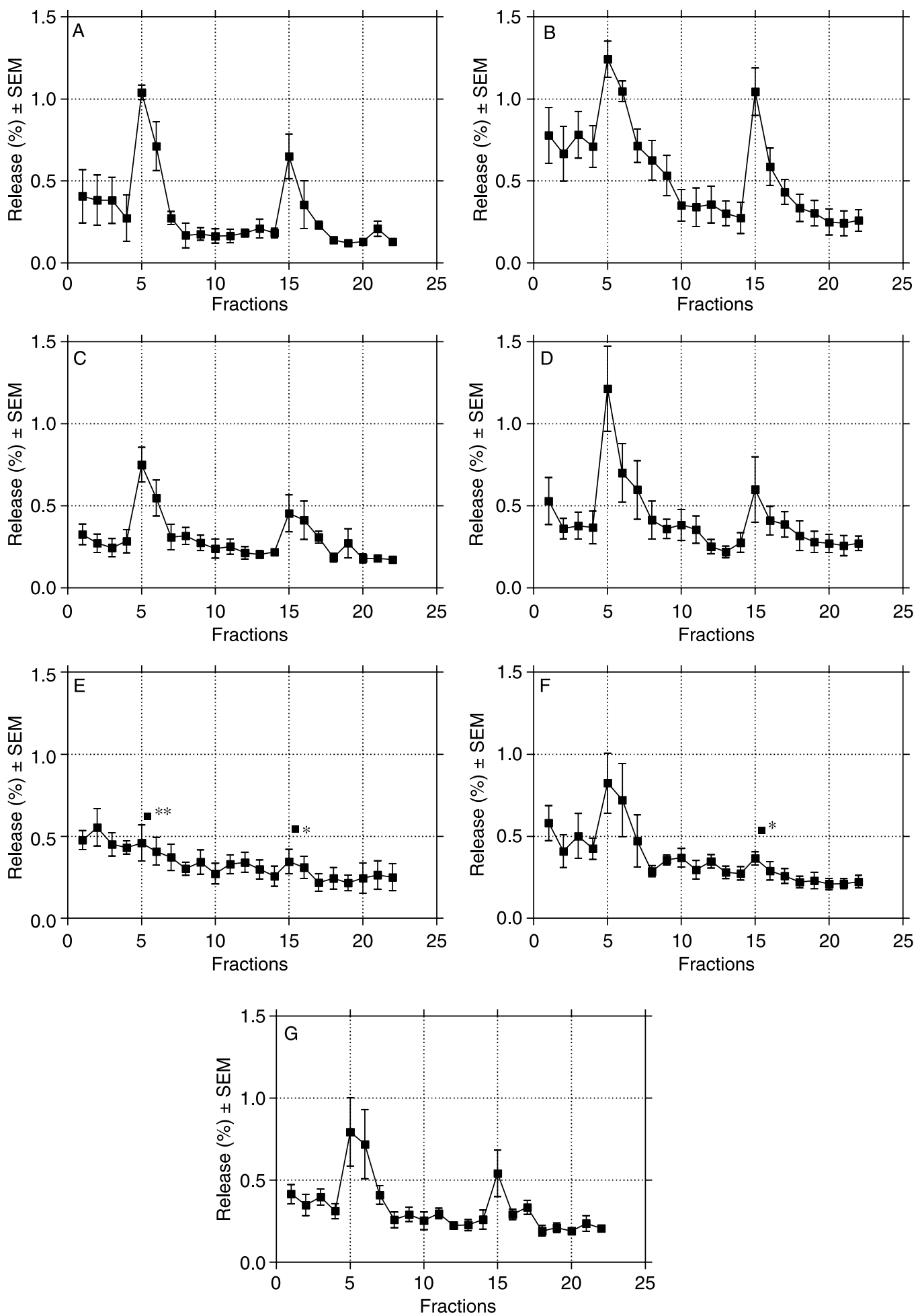

Figure 3 EFS-evoked fractional $\left[{ }^{3} \mathrm{H}\right]$ noradrenaline release from cervical samples at oestrus (A), on days 7 (B), 14 (C) and 21 (D) of pregnancy, and on postpartum days $1(\mathrm{E}), 7(\mathrm{~F})$ and $14(\mathrm{G}) . *$ and $* *$ denote $P<0.05$ and $P<0.01$ as compared with the non-pregnant value, respectively.

the adrenergic nerve function than the transmitter release. An alternative explanation for this contradiction is that the decrease in cervical uptake capacity is solely a result of a 'spacing' effect due to the growth of the cervix during pregnancy. In the early postpartum period, however, both parameters indicate inhibition in the cervix. This deterioration of the cervical adrenergic function could be explained by the intensive physical stretching during 

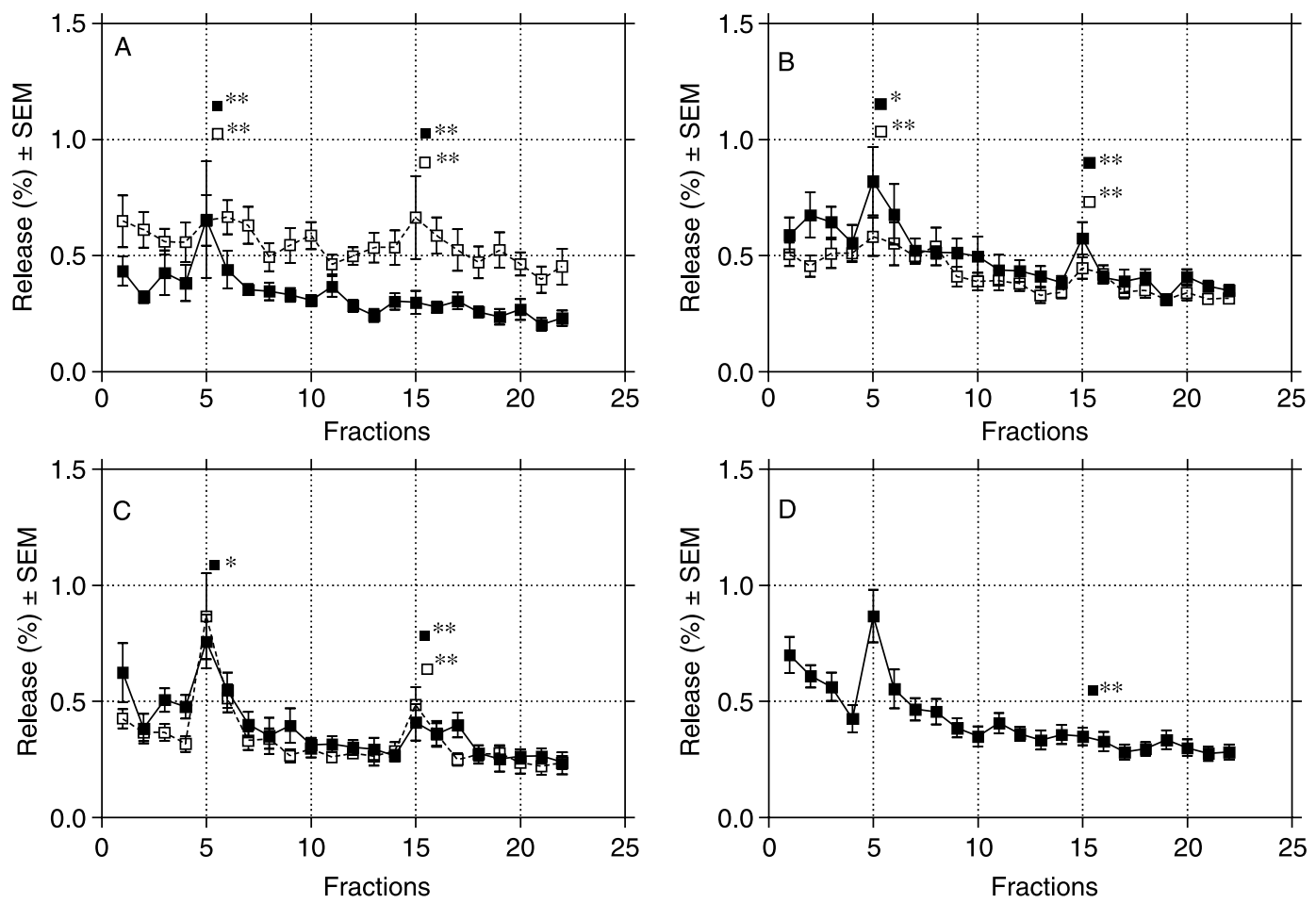

Figure 4 EFS-evoked fractional $\left[{ }^{3} \mathrm{H}\right]$ noradrenaline release from postpartum myometrial samples on days 1 (A), 7 (B), 14 (C) and 28 (D). * and ** denote $P<0.05$ and $P<0.01$ as compared with the non-pregnant value, respectively. In $\mathrm{A}-\mathrm{C}, \boldsymbol{\square}$ and $\square$ indicate release from the implantation and interimplantation sites, respectively (distinction between the two sites is not possible 21 days after delivery).

delivery. Distension was suggested previously to be a factor responsible for denervation in the uterus and bladder too (Owman et al. 1980, Tammela et al. 1990).

It was demonstrated that the total amount of nerve growth factor (NGF) and its mRNA are increased substantially by late pregnancy and return to the mature virgo level by 7 days after delivery (Varol et al. 2000). This newly synthesized growth factor is probably responsible for the reinnervation of the myometrium and the cervix. This concept is supported by the correlation between the NGF level of a target organ and its sympathetic innervation (Korsching \& Thoenen 1983). However, this correlation is missing in the female reproductive tract of the guinea-pig and rat, indicating that NGF is not the predominant regulator of the innervation in these organs (Brauer et al. 2000). The other possible key factor in gestational denervation and postpartum restoration is the receptivity of the myometrium, as evidenced by in oculo transplantation experiments (Brauer et al. 1998). Myometrial samples from virgin guinea-pigs transplanted into the anterior eye chamber were organotypically innervated by the host superior cervical ganglion. In contrast, samples from postpartum donors were approached, but not innervated.

Early reinnervation is detected immunohistochemically $48 \mathrm{~h}$ after delivery (Haase et al. 1997). However, our results indicate that the functions of the noradrenergic nerves in the myometrium and cervix have not recovered completely by postpartum weeks 4 and 2, respectively.
The basic mechanism of pregnancy-induced degeneration of the adrenergic fibres in the myometrium and cervix remains enigmatic, as does the reinnervation following delivery. Our results contribute to an understanding of the phenomenon, as the functional deterioration has been shown to start earlier than the structural denervation, and the restoration requires a long period. Our results lead us to conclude that superfusion can be utilized as a model system for investigation of the effects of pharmacological manipulation and pathological states (for example, pregnancy-induced hypertension or gestational diabetes) on the denervation procedure.

\section{Acknowledgements}

The author's declare that there is no conflict of interest that would prejudice the impartiality of this scientific work. I Zupkó is grateful for support from János Bolyai Research Fellowship.

\section{References}

Adham N \& Schenk EA 1969 Autonomic innervation of the rat vagina, cervix and uterus and its cyclic variation. American Journal of Obstetrics \& Gynecology 104 508-516.

Alm P, Owman C, Sjöberg NO \& Thorbert G 1979 Uptake and metabolism of $\left[{ }^{3} \mathrm{H}\right]$ norepinephrine in uterine nerves of pregnant guinea pig. American Journal of Physiology Cell Physiology 236 C277-C285.

Bell C 1972 Autonomic nervous control of reproduction: circulatory and other factors. Pharmacological Reviews 24 657-736. 
Bell C \& Malcolm SJ 1978 Observation on the loss of catecholamine fluorescence from intrauterine adrenergic nerves during pregnancy in the guinea-pig. Journal of Reproduction and Fertility 53 51-58.

Brauer MM, Lincoln J, Blundell D \& Corbacho A 1992 Postnatal development of noradrenaline-containing nerves of the rat uterus. Journal of the Autonomic Nervous System 39 37-49.

Brauer MM, Burnstock G, Thrasivoulou C \& Cowen T 1998 In oculo transplants of myometrium from postpartum guinea pigs fail to support sympathetic reinnervation. Journal of Anatomy 193 509-517.

Brauer MM, Shockley KP, Chávez R, Richeri A, Cowen T \& Crutcher KA 2000 The role of NGF in pregnancy-induced degeneration and regeneration of sympathetic nerves in the guinea pig uterus. Journal of the Autonomic Nervous System 79 19-27.

Bryman I, Norstrom A, Dahlstrom A \& Lindblom B 1987 Immunohistochemical evidence for preserved innervation of the human cervix during pregnancy. Gynecologic and Obstetric Investigation $2473-79$.

Engstrom T, Bratholm P, Vilhardt H \& Christensen NJ 1997 Effect of pregnancy on rat myometrial beta 2-adrenoceptor mRNA and isoproterenol-induced relaxation of isolated uterine strips. Journal of Endocrinology 153 393-399.

Fried G, Hammarström M \& Dahlin I 1985 Reduced uptake of noradrenaline into storage vesicles from the pregnant uterus. Acta Physiologica Scandinavica 123 311-316.

Haase EB, Buchman J, Tietz AE \& Schramm LP 1997 Pregnancyinduced uterine neuronal degeneration in the rat. Cell \& Tissue Research 288 293-306.

Hervonen A, Kanerva L \& Lietzen R 1973 Histochemically demonstrable catecholamines and cholinesterases of the rat uterus during estrus cycle, pregnancy and after estrogen treatment. Acta Physiologica Scandinavica 87 283-288.

Juorio AV, Chedrese PJ \& Li XM 1989 The influence of ovarian hormones on the rat oviductal and uterine concentration of noradrenaline and 5-hydroxytryptamine. Neurochemical Research $\mathbf{1 4}$ $821-827$.

Klukovits A, Gáspár R, Sántha P, Jancsó G \& Falkay G 2002 Functional and histochemical characterization of a uterine adrenergic denervation process in pregnant rats. Biology of Reproduction $\mathbf{6 7}$ 1013-1017.

Korsching S \& Thoenen T 1983 Nerve growth factor in sympathetic ganglia and corresponding target organs of the rat: correlation with density of sympathetic innervation. PNAS 80 3513-3516.

Legrand C, Mhaouty S, Rigolot C \& Maltier JP 1993 Heterogeneity of alpha-2 adrenoceptors in pregnant rat uterus: identification of subtypes and autoradiographic distribution. Journal of Pharmacology and Experimental Therapeutics 266 439-449.

Lundberg LM, Alm P \& Carlen B 1987 S-100 immunoreactive nerves in the guinea-pig uterus with reference to ultrastructural correlations: effects of chemical sympathectomy and pregnancy. Cell \& Tissue Research $250241-249$.

Mhaouty S, Cohen-Tannoudji J, Bouet-Alard R, Limon-Boulez I, Maltier JP \& Legrand C 1995 Characteristics of the $\alpha_{2} / \beta_{2}$-adrener- gic receptor-coupled adenylyl cyclase system in rat myometrium during pregnancy. Journal of Biological Chemistry 270 $11012-11016$.

Mione MC \& Gabella G 1991 Nerve fibres in the uterine artery increase in number in the pregnant guinea-pigs. Neuroreport 2 537-540.

Moustafa FA 1988 Changes in cholinergic and noradrenergic nerves in the pregnant and postpartum uterus of the albino rat and guinea pig. Acta Anatomy (Basel) 132 310-316.

Norstrom A \& Bryman I 1989 Uptake of ${ }^{3} \mathrm{H}$-norepinephrine in different segments of the human non-pregnant and pregnant uterus. Gynecologic and Obstetric Investigation 27 26-28.

Owman C 1981 Pregnancy induces degenerative and regenerative changes in the autonomic innervation of the female reproductive tract. Ciba Foundation Symposium $83252-279$.

Owman C, Alm P, Bjorklund A \& Thorbert G 1980 Extensive sympathetic denervation of the uterus during pregnancy as evidenced by tyrosine hydroxylase determinations in the guinea pig. Advances in Biochemistry \& Psychopharmacology 25 313-320.

Papka RE, Cotton JP \& Traurig HH 1985 Comparative distribution of neuropeptide tyrosine-, vasoactive intestinal polypeptide-, substance P-immunoreactive, acetylcholinesterase-positive and noradrenergic nerves in the reproductive tract of the female rat. Cell \& Tissue Research 242 475-490.

Tammela T, Lasanen L \& Waris T 1990 Effect of distension on adrenergic innervation of the rat urinary bladder. Urology Research 18 345-348.

Thorbert G, Alm P, Bjorklund AB, Owman C \& Sjöberg NO 1979 Adrenergic innervation of the human uterus. Disappearance of the transmitter and transmitter-forming enzymes during pregnancy. American Journal of Obstetrics \& Gynecology 135 223-226.

Van Orden DE, Goodale DB, Baker HA, Farley DB \& Bhatnagar RK 1980 Uterine catecholamines and prostaglandins during the estrous cycle of the rat. Endocrinology 106 1650-1654.

Varol FG, Duchemin AM, Neff NH \& Hadjiconstantinou M 2000 Nerve growth factor (NGF) and NGF mRNA change in rat uterus during pregnancy. Neuroscience Letters 294 58-62.

Wikland M, Lindblom B, Dahlstrom A \& Haglid KG 1984 Structural and functional evidence for the denervation of human myometrium during pregnancy. Obstetrics \& Gynecology 64 503-509.

Zoubina EV \& Smith PG 2001 Sympathetic hyperinnervation of the uterus in the estrogen receptor alpha knock-out mouse. Neuroscience 103 237-244.

Received 19 May 2005

First decision 23 June 2005

Revised manuscript received 9 August 2005

Accepted 16 August 2005 